OPEN ACCESS

Edited by:

Afshin A. Divani,

University of Minnesota, USA

Reviewed by:

Ricky Chow,

Boston Scientific, USA

Eugene Lin

St. Vincent Mercy

Medical Center, USA

*Correspondence:

Pervinder Bhogal

bhogalweb@aol.com

Specialty section:

This article was submitted to

Endovascular and Interventional

Neurology,

a section of the journal

Frontiers in Neurology

Received: 23 September 2016 Accepted: 13 January 2017

Published: 02 February 2017

Citation:

Bhogal P, AIMatter M, Bäzner $\mathrm{H}$,

Ganslandt O, Henkes H and

Aguilar Pérez M (2017) Flow

Diversion for the Treatment of MCA

Bifurcation Aneurysms - A Single

Centre Experience.

Front. Neurol. 8:20.

doi: 10.3389/fneur.2017.00020

\section{Flow Diversion for the Treatment of MCA Bifurcation Aneurysms-A Single Centre Experience}

\author{
Pervinder Bhogal ${ }^{\star *}$, Muhammad AlMatter ${ }^{1}$, Hansjörg Bäzner', Oliver Ganslandt ${ }^{3}$, \\ Hans Henkes ${ }^{1,4}$ and Marta Aguilar Pérez
}

${ }^{1}$ Neuroradiologic Clinic, Klinikum Stuttgart, Stuttgart, Germany, ${ }^{2}$ Neurologic Clinic, Klinikum Stuttgart, Stuttgart, Germany, ${ }^{3}$ Neurosurgical Clinic, Klinikum Stuttgart, Stuttgart, Germany, ${ }^{4}$ Medizinische Fakultät der Universität Duisburg-Essen, Essen, Germany

Background: Intracranial aneurysms located at the bifurcation of the middle cerebral artery (MCA) can often be challenging for the neurointerventionalist. We aimed to evaluate the efficacy and safety of flow diverting stents (FDS) in the treatment of these aneurysms.

Materials and methods: We retrospectively reviewed our prospectively maintained database to collect information for all patients with unruptured saccular bifurcation MCA aneurysms treated with FDS between January 2010 and January 2016. In addition to demographic data, we recorded the location, aneurysm characteristics, previous treatments, number and type of FDS, complications, and clinical and angiographic follow-up.

Results: Our search identified 13 patients ( 7 males) with an average age of 61.7 years (47-74 years). All patients had a single bifurcation aneurysm of the MCA, and none of the aneurysms were acutely ruptured. The average fundus size of the saccular aneurysms was $3 \mathrm{~mm}$ (range 1.5-10 mm). Follow-up studies were available for 12 patients. Based on the most recent follow-up angiograms, six aneurysms (50\%) were totally occluded; five aneurysms (41.7\%) showed only a small remnant; and one aneurysm (8.3\%) remained unchanged. One patient suffered from an ischemic stroke with resultant permanent hemiparesis (mRS 3). In another case, there was an in-stent thrombosis during the intervention, which resolved upon intra-arterial infusion of Eptifibatide (mRS 0). There were no intra-operative vessel or aneurysm ruptures and no mortalities. Angiography of the covered MCA branches showed no change in the caliber or flow of the vessel in six (50\%), a reduction in caliber in five (41.7\%), and a complete occlusion in one (8.3\%). All caliber changes and occlusions of the vessels were asymptomatic.

Conclusion: In our series, $91.7 \%$ of treated MCA bifurcation aneurysms were either completely occluded or showed only a small remnant with a good safety profile. Flow diversion of MCA bifurcation aneurysms should be considered as an alternative treatment strategy when microsurgical clipping or alternative endovascular treatment options are not feasible.

Keywords: flow diverter, pipeline embolization device, MCA aneurysm, MCA bifurcation, Stents, P64 


\section{INTRODUCTION}

Since the publication of the International Subarachnoid Aneurysm Trial, intracranial aneurysms are being increasingly treated via the endovascular approach as an alternative for craniotomy and surgical clipping (1). Aneurysms of the middle cerebral artery (MCA) remain, however, challenging for the neurointerventionist as they most commonly arise at a bifurcation of the vessel and frequently have a wide neck that can incorporate one or more branches (2), rendering traditional coiling difficult and necessitating the use of adjunctive devices such as balloon remodeling (3-7) or stent-assisted coiling (8-12). Over the last few years, flow diversion has proved to be a feasible and efficacious approach for the treatment of sidewall and dissecting aneurysms (13-19) even though long-term clinical data are still unavailable. The role of flow diverter stents (FDS) in treating bifurcation aneurysms remains, however, unclear. In this report, we review our experience in treating MCA bifurcation aneurysms with flow diversion as the primary approach or secondary therapy after previous coiling or clipping with subsequent recanalization/ aneurysm residual.

\section{PATIENTS AND METHODS}

\section{Population}

We retrospectively reviewed our prospectively maintained database to identify patients with aneurysms of the MCA bifurcation who were treated with flow diversion. Records were made of demographic data, clinical presentation, location and morphology of the aneurysms, the endovascular procedure, the postoperative complications, and the latest angiographic and clinical follow-up.

\section{Definition of MCA Bifurcation Aneurysm}

We chose to categorize aneurysms arising at the first main division of the M1 trunk and those arising at an early division of a dominant superior or inferior trunk as MCA bifurcation aneurysms. Aneurysms of the M1 segment and distal to the MCA bifurcation were excluded.

\section{Endovascular Treatment}

Informed consent was obtained prior to the intervention in all patients. A loading dose of two antiplatelet agents (aspirin $100 \mathrm{mg}$ per day and clopidogrel $75 \mathrm{mg}$ per day) was administered in every case, and the adequacy of the antiplatelet therapy was measured using the Multiplate Analyzer (Roche, Germany). Patients found resistant to clopidogrel received $2 \times 90 \mathrm{mg}$ ticagrelor daily. All therapeutic interventions were performed under general anesthesia. Arterial access was carried out through a standard $6 \mathrm{Fr}$ right common femoral route in all cases. A bolus dose of heparin $(5,000 \mathrm{IU})$ was administered after securing the introducer sheath followed by repeat bolus doses every hour to maintain the activated clotting time between 2 and 2.5 times the baseline. The post-procedural antiplatelet regimen consisted of clopidogrel/ ticagrelor continued for 12 months following treatment and aspirin continued for life.

A pipeline embolization device (PED) was used in one case (Covidien, Irvine, CA, USA), the p64 flow modulation device
(Phenox, Bochum, Germany) was used in all other cases. The choice of flow diverter was down to the operator, and we only have the p64 and PED available in our department. The PED is one of the most widely studied devices and is made of $25 \%$ platinum and $75 \%$ nickel-cobalt-chromium alloy with a porosity of $65-70 \%$. It is available in a variety of different sizes and diameters and multiple telescoped PED's can be used to alter the porosity (20). The p64 is a braided flow diverting stent composed of 64 nitinol wires. Two platinum wires are wrapped around the shaft and assist in the radio opacity of the device. The 64 wires are grouped into 8 bundles proximally, with each bundle consisting of 8 wires. A radio-opaque marker is attached to end of each of these bundles. The porosity of the device is $51-60 \%$. The p64 is unique amongst flow diverters in that it is mechanically detached and can be resheathed even after complete deployment.

\section{Clinical and Angiographic Follow-up}

All patients were evaluated clinically and neurologically prior to the treatment and during the postoperative hospital stay, another clinical and neurological evaluation was performed at every follow-up as well. Initial follow-up catheter angiography was performed at 3 months. The extent of the aneurysmal occlusion was graded as:

- 1-total occlusion, no contrast filling of the aneurysm sac (Raymond Roy I)

- 2-subtotal occlusion, minor residual sac filling or neck remnant (Raymond Roy II)

- 3-incomplete occlusion, substantial residual sac filling (Raymond Roy III)

- 4-unchanged, patent aneurysmal sac with constant morphology compared to the pretreatment angiogram.

\section{RESULTS}

\section{Population}

There were 13 patients matching our inclusion criteria ( 7 males) with an average age of 60 years ( $42-76$ years). The treated aneurysms were equally distributed between right and left. Three patients had a second aneurysm at a different location, one patient had two and another patient had four other intracranial aneurysms located elsewhere. All aneurysms were saccular with a fundus size ranging from 1.5 to $10 \mathrm{~mm}$ (average fundus size $3 \mathrm{~mm}$ ) and with the exception of one case all aneurysms had a dome/neck ratio of less than 1.5. Twelve aneurysms were located at the fist main MCA bifurcation (early bifurcation in two cases), one aneurysm was located at the bifurcation of each of the superior and inferior trunk. All patients were treated on an elective basis. The two fusiform aneurysms were previously clipped with incomplete occlusion. Four of the saccular aneurysms were previously treated by other modality (three were coiled and in one case there was an enlarging neck remnant after clipping and then coiling). The results are summarized in Table 1.

\section{Feasibility}

The delivery of the FDS was unproblematic in all cases. A single flow diverter was used in all cases. A PED was used in one 
TABLE 1 | Demographics, aneurysm characteristics, clinical, and radiological follow-up.

\begin{tabular}{|c|c|c|c|c|c|c|c|c|c|c|c|}
\hline $\begin{array}{l}\text { Patient } \\
\text { no. }\end{array}$ & Gender & Age & Side & $\begin{array}{l}\text { Dome } \\
(\mathrm{mm})\end{array}$ & $\begin{array}{l}\text { Neck } \\
(\mathrm{mm})\end{array}$ & $\begin{array}{l}\text { Previous } \\
\text { treatments }\end{array}$ & FDS (no. $\times$ type) & Occlusion & Covered branch & Complications & $\begin{array}{c}\text { Change in } \\
\text { baseline } \\
\text { mRS }\end{array}$ \\
\hline 1 & $\mathrm{~m}$ & 60 & $L$ & 2 & 2 & Surgery, coils & $1 \times p 64$ & 2, RRC ॥ & Unchanged & $\mathrm{N}$ & $\mathrm{N}$ \\
\hline 2 & $\mathrm{~m}$ & 64 & $\mathrm{R}$ & 2 & 2 & $\mathrm{~N}$ & $1 \times p 64$ & $1, \mathrm{RRC} \mid$ & Asymptomatic occlusion & $\mathrm{N}$ & $\mathrm{N}$ \\
\hline 3 & $f$ & 47 & $\mathrm{~L}$ & 1.5 & 1.5 & Coils & $1 \times p 64$ & $1, \mathrm{RRC} \mid$ & Unchanged & $\mathrm{N}$ & $\mathrm{N}$ \\
\hline 4 & $f$ & 50 & $\mathrm{~L}$ & 2 & 2 & Coils & $1 \times p 64$ & $1, \mathrm{RRC}$ I & Reduction in caliber & $\mathrm{N}$ & $\mathrm{N}$ \\
\hline 5 & $f$ & 60 & $\mathrm{R}$ & 4 & 4 & $N$ & $1 \times p 64$ & 2, RRC ॥ & Reduction in caliber & $\mathrm{N}$ & $\mathrm{N}$ \\
\hline 6 & $\mathrm{~m}$ & 58 & $\mathrm{R}$ & 2 & 3 & $\mathrm{~N}$ & $1 \times p 64$ & 2, RRC ॥ & Reduction in caliber & $\mathrm{N}$ & $\mathrm{N}$ \\
\hline 7 & $\mathrm{~m}$ & 60 & $\mathrm{~L}$ & 3 & 4 & $\mathrm{~N}$ & $1 \times p 64$ & 1, RRC I & Unchanged & $\mathrm{N}$ & $\mathrm{N}$ \\
\hline 8 & $\mathrm{~m}$ & 76 & $\mathrm{R}$ & 10 & 3.5 & $N$ & $1 \times p 64$ & 2, RRC ॥ & Reduction in caliber & $\mathrm{N}$ & $\mathrm{N}$ \\
\hline 9 & $f$ & 74 & $\mathrm{R}$ & 4 & 1.5 & $\mathrm{~N}$ & $1 \times p 64$ & 4 & Reduction in caliber & $\mathrm{N}$ & $\mathrm{N}$ \\
\hline 10 & $\mathrm{~m}$ & 58 & $L$ & 2 & 2 & $\mathrm{~N}$ & $1 \times p 64$ & NA & NA & $\mathrm{N}$ & $\mathrm{N}$ \\
\hline 11 & $\mathrm{~m}$ & 71 & $\mathrm{~L}$ & 2 & 3 & $\mathrm{~N}$ & $1 \times p 64$ & 2, RRC ॥ & Unchanged & Stroke & $Y(m R S 3)$ \\
\hline 12 & $f$ & 59 & $L$ & 3 & 1 & $\mathrm{~N}$ & $1 \times p 64$ & 1, RRC I & Unchanged & $\begin{array}{l}\text { Asymptomatic } \\
\text { thrombosis }\end{array}$ & N \\
\hline 13 & $f$ & 65 & $\mathrm{R}$ & 2 & 2 & $\mathrm{~N}$ & $\begin{array}{c}1 \times \text { pipeline } \\
\text { embolization device }\end{array}$ & 1, RRC I & Unchanged & $\mathrm{N}$ & $\mathrm{N}$ \\
\hline
\end{tabular}

case; all other patients were treated using the p64 flow modulation device.

\section{Angiographic Follow-up}

Follow-up studies were available for 12 patients with first follow-up catheter angiography performed at mean 3.1 months after treatment. Delayed angiography was performed at mean 15.8 months. There was complete aneurysmal occlusion in six cases (50\%) (Figure 1). Near-complete occlusion with only a neck remnant was achieved in a further five cases $(41.7 \%)$. A single case remained unchanged in our series; therefore, complete or near-complete occlusion was achieved in $91.7 \%$ of our cases.

The covered branches remained unchanged in caliber and flow in six cases (50\%). In five cases, there was a reduction in the caliber of the covered branch but the vessel remained patent with anterograde flow (Figure 1). There was a single case of asymptomatic occlusion of the covered branch $(8.3 \%)$. All the cases where the covered vessel caliber was reduced or completely occluded were clinically asymptomatic.

\section{Complications}

There was one case of an immediate thrombosis of the FDS, which resolved secondary to intra-arterial infusion of Eptifibatide and the patient recovered without neurological sequelae. One patient developed hemiparesis four days after the implantation of the FDS. The emergent MRI showed restricted diffusion in the basal ganglia and centrum semiovale. The immediate angiogram showed no in-stent thrombosis or vessel occlusion. Although the exact cause of the infarction in this case is not know, it is possible that a drop in blood pressure plus reduced flow through the FDS may have resulted in decreased perfusion to the infarcted region (Figure 2).

\section{DISCUSSION}

The MCA is the larger of the two terminal branches of the internal carotid artery. Over its course the MCA is divided into four segments: the M1 (sphenoidal) segment, the M2 (insular) segment, the M3 (opercular) segment, and the M4 (cortical) segments (21). The branching pattern of the main trunk of the MCA is variable with a bifurcation being the most common: absence of a main division in 6\%, bifurcation in 64\%, trifurcation in $29 \%$, and quadrifurcation in $1 \%$ of people. The location of the bifurcation depends on the length of the M1 Segment. The main divisions are of equal diameter in only $15 \%$ of the cases with the inferior trunk being dominant in 50\% (22).

Aneurysms of the MCA occur most often at the main division point (23). In a review of a population-based series of 3,005 patients with 4,253 intracranial aneurysms, 1,704 were MCA aneurysms, of which $1,385(81 \%)$ were located at the main bifurcation of the MCA. The percentage of aneurysms located at the main bifurcation was even higher among ruptured MCA aneurysms (89\%) (2). Elsharkawy et al. (24) analyzed 1,009 aneurysms located on the MCA to determine if there were particular risk factors associated with a risk of rupture. In this study, location at the MCA bifurcation, wall irregularity, and non-spherical shape were all identified as risks for rupture. Interestingly, it was also seen that $26 \%$ of patients with ruptured MCA bifurcation aneurysms were classified as small $(<7 \mathrm{~mm})$ and that this was significantly greater than the percentage of patients with large (15-24 $\mathrm{mm})$ and giant ( $\geq 25 \mathrm{~mm})$ aneurysms, which presented with rupture in 15 and $2 \%$ of cases, respectively. This highlights, that at least in this location, small aneurysms carry a not insignificant risk of rupture.

From an anatomical perspective MCA bifurcation aneurysms are often wide necked and may incorporate one or more branches. This can be challenging for traditional endovascular approaches such as coiling without adjunctive devices $(2,25,26)$. In the study of Jin et al. (27), 103 aneurysms of the MCA bifurcation were treated with only coiling. The post-coiling angiogram in these patients showed a complete occlusion in $27.2 \%$ and residual neck in 58.3\%. At follow-up angiography (mean 30 months), recanalization was seen in $25 \%$ of cases and just over $20 \%$ of these recanalized aneurysms were deemed completely occluded on post-coiling angiography. Other authors have also published 


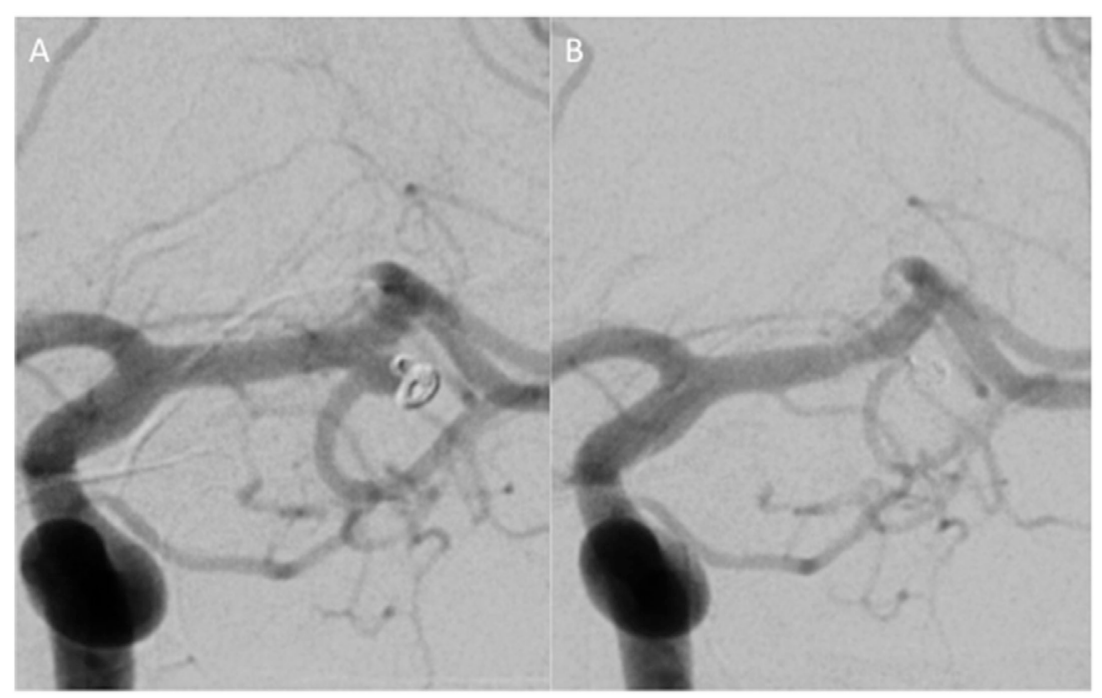

FIGURE 1 | A small neck recurrence after a previous coiling (A). Repeat treatment using coils would have necessitated a stent into the inferior branch, and therefore, it was felt an alternative strategy would be to place a single p64 FDS into the superior middle cerebral artery trunk. A follow-up angiogram performed 3 months later $\mathbf{B}$ ) showed on contrast enhancement of the aneurysm and a reduction in the caliber of the size of the inferior trunk but with persistent anterograde flow. The patient was neurologically intact, and there were no clinical consequences of the vessel modification.

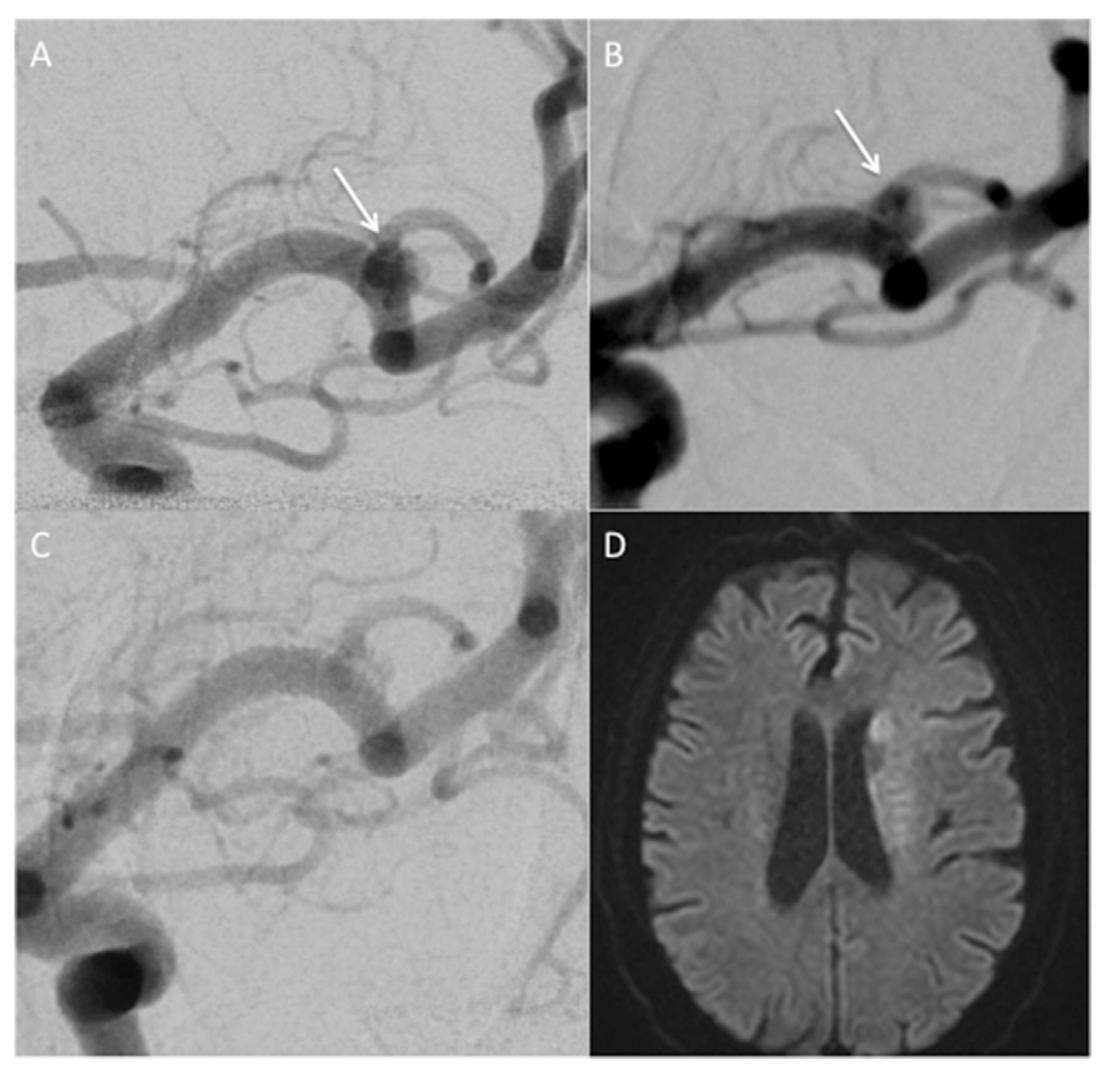

FIGURE 2 | A patient treated with a single p64 FDS for a middle cerebral artery bifurcation anerurysm. An incidental untreated bifurcation aneurysm (A). The same aneurysm in a different projection shows a wide necked saccular MCA bifurcation (B). There were no intra-operative complications and immediately post-procedure the patient awoke with baseline neurology. Five days post-procedure, the patient developed a right hemiparesis. Catheter angiography at this time (C) showed all branches were patent with anterograde flow and minimal filling of the aneurysm. An MRI showed restricted diffusion (D). 
their experience of MCA aneurysm treatment involving endovascular techniques; for example, Bracard et al. reviewed 152 MCA aneurysms treated by coil occlusion. They showed complete or near-complete occlusion in $84.2 \%$ of aneurysms, of which $80.2 \%$ persisted at the 5 -year follow-up (28). In a large retrospective analysis of 300 consecutive endovascularly treated MCA aneurysms (80\% ruptured), complete or near-total occlusion was achieved in $91 \%$ of cases (25). Similarly, Zaidat et al. (29) reviewed their endovascular treatment of 161 consecutive MCA aneurysms and reported technical feasibility of $98.8 \%$ and a retreatment rate of $11 \%$. In the meta-analysis of 12 studies performed by Brinjikji et al., they noted an overall occlusion rate (complete or near-complete occlusion) of $82.4 \%$ with an overall procedure-related permanent morbidity/mortality rate of $5.1 \%$ for unruptured aneurysms. While these latter studies are useful, a major difficulty in their interpretation is they include all MCA aneurysms together with no separation based on anatomical location.

In order to address the various anatomical abnormalities that may be encountered when treating MCA bifurcation aneurysms, various techniques have been developed and include: balloon remodeling (3-7), stent-assisted coiling (7-9, 11, 12), neck-bridging devices $(30,31)$, and intra-aneurysmal flow disrupters (32-35).

Eboli et al. (36) recently published their series of $184 \mathrm{MCA}$ bifurcation aneurysms treated endovascularly. In this series, stent-assisted coiling was required in 70 cases (38\%), and only 3 cases $(1.6 \%)$ required " $Y$ " stenting. They achieved an initial total occlusion rate of 59.8\%; however, on follow-up angiography (mean 41 months) complete aneurysm occlusion was seen in $90.1 \%$ of patients with a further $6.1 \%$ of patients having a stable remnant. The overall peri-procedural morbidity was $3.8 \%$ and the mortality rate in the unruptured cohort was $0 \%$.

The Woven EndoBridge [WEB (Sequent Medical, Aliso Viejo, CA, USA)] is an intra-saccular device designed to disrupt the intra-aneurysmal flow at the level of the neck to encourage intra-aneurysmal thrombosis. Although some authors reported high feasibility of this device with promising early and midterm post-procedural angiographic results (32-34), the follow-up study by Cognard and Januel reported worsening at follow-up in $71.5 \%$ in their series of 14 patients with wide-neck bifurcation aneurysms (of which 11 were at the MCA bifurcation) with compression of the cage demonstrated in 8 of the 14 cases (37). Additionally, the available sizes of the WEB device may render it unsuitable to small wide-necked aneurysms. The pCONus (Phenox, Bochum, Germany) device is an electrolytically detachable self-expanding nitinol implant with four distal petals designed to open inside the aneurysm providing support for coiling of wide-neck bifurcation aneurysms. Aguilar-Pérez et al. recently published their experience with the pCONus neck-bridging device for the treatment of wide-necked aneurysms. This series included $11 \mathrm{MCA}$ aneurysms with complete occlusion of 6 aneurysms (54.5\%) at follow-up and only neck remnant in 3 cases (27.2\%) (30).

Since their introduction, flow diverter stents (FDS) have gained popularity for the treatment of intracranial aneurysms. The occlusion of an aneurysm by FDS is initially by the promotion of intra-aneurysmal thrombosis through induced flow stasis. The blood's flow though the struts of a FDS depends on flow demands and thus preserving the patency of covered branches where flow is needed (38). For example, even relatively small arteries such as the anterior choroidal artery remain patent after coverage by FDS as was recently shown by Neki et al. (39). Covered branches with an adequate collateral arterial supply, such as the ophthalmic artery, where the orbit enjoys a rich collateral blood supply through branches of the external carotid artery, frequently undergo spontaneous, asymptomatic occlusion (40). Rangel-Castilla et al. recently published their longer-term results of 82 aneurysms treated with FDS with an emphasis on covered branches (41). In this study of 76 covered ophthalmic arteries, $10.5 \%$ were occluded (clinically asymptomatic), 28 posterior communicating arteries were covered with $10.7 \%$ of the vessels occluded (clinically asymptomatic), and 21 covered anterior choroidal arteries with no evidence of occlusion. This study also reported two cases where the anterior cerebral artery was covered and there was occlusion with filling of the A2 segment via the contralateral anterior cerebral artery. Therefore, there is evidence that branch occlusion can be asymptomatic. However, this may not necessarily be the case in more distal locations such as at the MCA bifurcation.

Yavuz et al. (42) used the PED to treat 25 MCA aneurysms located at or distal to the bifurcation in 21 patients and reported a complete occlusion in 21 of the cases $(84 \%)$. There were no mortalities, and apart from one patient who developed ischemia several days after the procedure (which was attributed to vasospasm by the authors), there were no significant peri-procedural morbidities. There was reduced filling of six and total occlusion of three of the covered branches, all of which remained clinically asymptomatic. The authors concluded that the PED is a safe and feasible option in treating aneurysms arising at the MCA bifurcation. The results reported by Caroff et al. (43) were not so promising. In their retrospective review of 14 patients harboring 15 saccular MCA bifurcation aneurysms treated with FDS, the authors reported ischemic complications in $43 \%$ of the cases detected on MRI, and although, there were no mortalities, procedure-related morbidities reached $21 \%$ on follow-up, most of these were related to occlusion or slow flow in the covered branches. Complete occlusion was, however, achieved in only $62 \%$ of the treated aneurysms. In another report by Briganti et al. (44), total occlusion of the MCA bifurcation aneurysms was achieved in $80 \%$ with the rest of the aneurysms being partially occluded. This series included 14 patients harboring 15 MCA aneurysms of which 13 were located at the MCA bifurcation, all of which were treated using the PED. Of the 13 side branches covered by the PED, follow-up angiographic studies showed reduced flow in 6 and total occlusion of 3 of them. The authors reported ischemic complications in $27 \%$ of the cases with permanent neurological deficient in $21 \%$. Topcuoglu et al. (45) recently published their series of 29 aneurysms of the MCA treated with flow diversion, 6 of which occurred at the true bifurcation of the MCA (defined as the division of the MCA in superior and inferior trunks). Of these 6 cases, all of which were treated with the Silk FDS (Balt, Montmercy, France), occlusion of the covered branch occurred in $50 \%$ of cases, none of which 
resulted in morbidity or mortality. In our series, we achieved a complete occlusion in $50 \%$ of patients and near-complete occlusion in $41.7 \%$. We had no mortalities and only one case of permanent morbidity. We believe, as with flow diversion used in other sites, that the aneurysms with near-complete occlusion will continue to occlude over time as neo-endothelialization occurs; however, longer-term follow-up is required. In a single case, the aneurysm showed no change at delayed angiography (9 months), and we are unable to explain this phenomenon. The patient had no background medical conditions that could potentially interfere with neo-endothelialization nor did they demonstrate any abnormal response to the antiplatelet medication.

Saleme et al. (46) sought to clarify the role of covered branches and collateral supply. They compared remodeling of the side braches covered after the deployment of flow diverters dividing the aneurysms in two groups based on whether the territory supplied by the side branch received a direct collateral supply or not. This study included the placement of FDS across the anterior cerebral artery, the anterior communicating artery, the terminal ICA, and the MCA (51.4\% of cases). They showed that in the group with a direct collateral supply $78.5 \%$ of covered branches had undergone narrowing or occlusion at 6 months, although no new strokes were seen on MR imaging. Hence, the authors suggest that symptomatic remodeling of covered side braches depends on the extent and type of collateral supply, and this is similar to the findings reported earlier by Rangel-Castilla et al. (39-41). One explanation of the lower occlusion rate observed with flow diversion for bifurcation aneurysms might be the persistent flow through the covered braches incorporated by the aneurysm. Fahed et al. (47) compared flow diversion with and without occlusion of the jailed branch in 14 wide-neck aneurysms induced in 8 canines and found that occlusion of the jailed branch resulted in better occlusion rates of aneurysmal occlusion. Patent aneurysms were associated with leaks or holes in the neo-intima covering the aneurysm neck. The authors concluded that persistent flow to the jailed branch is a potential cause of treatment failure after flow diversion for bifurcation aneurysms. Furthermore, it is also worth remembering that the porosity of FDS is known to alter with curves and this appears to be most marked for FDS deployed across bifurcation aneurysms and on the outer edge curves of vessels $(48,49)$. This effect has been studied for both the PED and the Silk flow diverters with similar results and it is likely that the same effect will be seen with the p64.

Despite the plethora of currently available modality for the treatment of MCA aneurysms, considering the relatively straight forward access, the good outcome after clipping and the ability for simultaneous removal of a space occupying hematoma in cases of ruptured aneurysms, a surgical approach remains the principal treatment of MCA aneurysms in many centers $(2,50$, 51). In their series of 282 ruptured and 261 unruptured MCA aneurysms, Rodríguez-Hernández and colleagues reported complete aneurysm obliteration in $98.3 \%$ and good clinical outcomes in $92 \%$ of patients with unruptured and $70.2 \%$ with ruptured aneurysms (52). In a review of the literature by Yang and Haung, the authors favored the microsurgical approach for the definitive management of MCA aneurysms. The reviewed surgical series reported occlusion rates between 90 and $89.3 \%$ with good clinical outcomes in $92-100 \%$ of unruptured and $70-80 \%$ of ruptured MCA aneurysms treated with clipping. The authors also suggested that the significantly higher retreatment rated and lower occlusion rates of the endovascular approach would offset the favorable clinical outcome in the short term of the less invasive approach (53).

Our study has several limitations. The sample size is small and the treated aneurysms are heterogeneous. Another limiting factor is that flow diversion was not the primary treatment in six cases $(42.8 \%)$, rather implemented as a secondary therapy for persistent aneurysmal perfusion after coiling or clipping. The results are also limited by the relatively short follow-up period (13 months on average), especially because the definitive results of this modality depend on the progressive reduction of flow inside the aneurysmal sac. Although one type of flow diverter stents, namely the p64, was used in all but one case in our series, we believe that the relatively inferior results in comparison to other endovascular or surgical modalities are related to the special anatomic consideration of the MCA bifurcation, rather than the technical specification of the flow modulation device.

\section{CONCLUSION}

Based on our small series, flow diversion for the treatment of bifurcation MCA aneurysms is feasible with good angiographic results and acceptable complication rates. However, compared to the results of other endovascular techniques and to surgery, total occlusion of bifurcation MCA aneurysms seems to be less frequent with flow diversion. Therefore, we believe that flow diversion should be reserved for cases where other treatment modalities are deemed unfeasible or carry excessive risk.

\section{ETHICS STATEMENT}

As this study was retrospective in design and all identifying information removed from images and data, local ethics committee approval was not required. All patients gave informed consent for the procedure. Consent for publication was not required and all identifiable information removed from the manuscript.

\section{AUTHOR CONTRIBUTIONS}

$\mathrm{PB}$ - data collection, imaging review, manuscript preparation; MA - data collection, imaging review, manuscript preparation; $\mathrm{HB}$ - manuscript editing, language correction; $\mathrm{HH}$ - manuscript editing, manuscript preparation, concept; OG-manuscript editing, concept; and MAP-guarantor.

\section{FUNDING}

There is no funding for this article. 


\section{REFERENCES}

1. Molyneux A, Kerr R, Stratton I, Sandercock P, Clarke M, Shrimpton J, et al. International Subarachnoid Aneurysm Trial (ISAT) of neurosurgical clipping versus endovascular coiling in 2143 patients with ruptured intracranial aneurysms: a randomised trial. Lancet (2002) 360:1267-74. doi:10.1016/ S0140-6736(02)11314-6

2. Dashti R, Hernesniemi J, Niemelä $M$, Rinne J, Porras $M$, Lehecka $M$, et al. Microneurosurgical management of middle cerebral artery bifurcation aneurysms. Surg Neurol (2007) 67:441-56. doi:10.1016/j.surneu.2006.11.056

3. Pierot L, Cognard C, Spelle L, Moret J. Safety and efficacy of balloon remodeling technique during endovascular treatment of intracranial aneurysms: critical review of the literature. AJNR Am J Neuroradiol (2012) 33:12-5. doi:10.3174/ajnr.A2403

4. Vendrell JF, Menjot N, Costalat V, Hoa D, Moritz J, Brunel H, et al. Endovascular treatment of 174 middle cerebral artery aneurysms: clinical outcome and radiologic results at long-term follow-up. Radiology (2009) 253:191-8. doi:10.1148/radiol.2531082092

5. Moret J, Cognard C, Weill A, Castaings L, Rey A. The "remodelling technique" in the treatment of wide neck intracranial aneurysms. Angiographic results and clinical follow-up in 56 cases. Interv Neuroradiol (1997) 3:21-35. doi:10.1177/159101999700300103

6. Baldi S, Mounayer C, Piotin M, Spelle L, Moret J. Balloon-assisted coil placement in wide-neck bifurcation aneurysms by use of a new, compliant balloon microcatheter. AJNR Am J Neuroradiol (2003) 24:1222-5.

7. Pierot L, Biondi A. Endovascular techniques for the management of wideneck intracranial bifurcation aneurysms: a critical review of the literature. J Neuroradiol (2016) 43:167-75. doi:10.1016/j.neurad.2016.02.001

8. Vendrell JF, Costalat V, Brunel H, Riquelme C, Bonafe A. Stent-assisted coiling of complex middle cerebral artery aneurysms: initial and midterm results. AJNR Am J Neuroradiol (2011) 32:259-63. doi:10.3174/ajnr.A2272

9. Piotin M, Blanc R, Spelle L, Mounayer C, Piantino R, Schmidt PJ, et al. Stent-assisted coiling of intracranial aneurysms clinical and angiographic results in 216 consecutive aneurysms. Stroke (2010) 41:110-5. doi:10.1161/ STROKEAHA.109.558114

10. Biondi A, Janardhan V, Katz JM, Salvaggio K, Riina HA, Gobin YP. Neuroform stent-assisted coil embolization of wide-neck intracranial aneurysms: strategies in stent deployment and midterm follow-up. Neurosurgery (2007) 61:460-9. doi:10.1227/01.NEU.0000290890.62201.A9

11. Chalouhi N, Jabbour P, Singhal S, Drueding R, Starke RM, Dalyai RT, et al. Stent-assisted coiling of intracranial aneurysms predictors of complications, recanalization, and outcome in 508 cases. Stroke (2013) 44:1348-53. doi:10.1161/STROKEAHA.111.000641

12. Henkes H, Bose A, Felber S, Miloslavski E, Berg-Dammer E, Kühne D. Endovascular coil occlusion of intracranial aneurysms assisted by a novel self-expandable nitinol microstent (neuroform). Interv Neuroradiol (2002) 8:107-19. doi:10.1177/159101990200800202

13. Fischer S, Vajda Z, Perez MA, Schmid E, Hopf N, Bäzner H, et al. Pipeline embolization device (PED) for neurovascular reconstruction: initial experience in the treatment of 101 intracranial aneurysms and dissections. Neuroradiology (2011) 54:369-82. doi:10.1007/s00234-011-0948-x

14. Lubicz B, Collignon L, Raphaeli G, De Witte O. Pipeline flow-diverter stent for endovascular treatment of intracranial aneurysms: preliminary experience in 20 patients with 27 aneurysms. World Neurosurg (2011) 76:114-9. doi:10.1016/j.wneu.2011.02.015

15. Briganti F, Leone G, Marseglia M, Mariniello G, Caranci F, Brunetti A, et al. Endovascular treatment of cerebral aneurysms using flowdiverter devices: a systematic review. Neuroradiol J (2015) 28:365-75. doi:10.1177/1971400915602803

16. Brinjikji W, Murad MH, Lanzino G, Cloft HJ, Kallmes DF. Endovascular treatment of intracranial aneurysms with flow diverters a meta-analysis. Stroke (2013) 44:442-7. doi:10.1161/STROKEAHA.112.678151

17. D'Urso PI, Lanzino G, Cloft HJ, Kallmes DF. Flow diversion for intracranial aneurysms: a review. Stroke (2011) 42:2363-8. doi:10.1161/ STROKEAHA.111.620328

18. Fischer S, Aguilar-Pérez M, Henkes E, Kurre W, Ganslandt O, Bäzner H, et al. Initial experience with p64: a novel mechanically detachable flow diverter for the treatment of intracranial saccular sidewall aneurysms. AJNR Am J Neuroradiol (2015) 36:2082-9. doi:10.3174/ajnr.A4420

19. Briganti F, Leone G, Marseglia M, Cicala D, Caranci F, Maiuri F. p64 Flow Modulation Device in the treatment of intracranial aneurysms: initial experience and technical aspects. J Neurointerv Surg (2016) 8(2):173-80. doi:10.1136/neurintsurg-2015-011743

20. Nelson PK, Lylyk P, Szikora I, Wetzel SG, Wanke I, Fiorella D. The pipeline embolization device for the intracranial treatment of aneurysms trial. AJNR Am J Neuroradiol (2011) 32:34-40. doi:10.3174/ajnr.A2421

21. Gibo H, Carver CC, Rhoton AL Jr, Lenkey C, Mitchell RJ. Microsurgical anatomy of the middle cerebral artery. J Neurosurg (1981) 54:151-69. doi:10.3171/jns.1981.54.2.0151

22. Türe U, Yaşargil MG, Al-Mefty O, Yaşargil DC. Arteries of the insula. J Neurosurg (2000) 92:676-87. doi:10.3171/jns.2000.92.4.0676

23. Elsharkawy A, Lehečka M, Niemelä M, Billon-Grand R, Lehto H, Kivisaari R, et al. A new, more accurate classification of middle cerebral artery aneurysms: computed tomography angiographic study of 1,009 consecutive cases with 1,309 middle cerebral artery aneurysms. Neurosurgery (2013) 73:94-102; discussion 102. doi:10.1227/01.neu.0000429842.61213.d5

24. Elsharkawy A, Lehečka M, Niemelä M, Kivelev J, Billon-Grand R, Lehto $\mathrm{H}$, et al. Anatomic risk factors for middle cerebral artery aneurysm rupture: computed tomography angiography study of 1009 consecutive patients. Neurosurgery (2013) 73:825-37; discussion 836-837. doi:10.1227/ NEU.0000000000000116

25. Mortimer AM, Bradley MD, Mews P, Molyneux AJ, Renowden SA. Endovascular treatment of 300 consecutive middle cerebral artery aneurysms: clinical and radiologic outcomes. AJNR Am J Neuroradiol (2014) 35:706-14. doi:10.3174/ajnr.A3776

26. Rinne J, Hernesniemi J, Niskanen M, Vapalahti M. Analysis of 561 patients with 690 middle cerebral artery aneurysms: anatomic and clinical features as correlated to management outcome. Neurosurgery (1996) 38:2-11. doi:10.1097/00006123-199601000-00002

27. Jin SC, Kwon OK, Oh CW, Bang JS, Hwang G, Park NM, et al. Simple coiling using single or multiple catheters without balloons or stents in middle cerebral artery bifurcation aneurysms. Neuroradiology (2013) 55:321-6. doi:10.1007/s00234-012-1119-4

28. Bracard S, Abdel-Kerim A, Thuillier L, Klein O, Anxionnat R, Finitsis S, et al. Endovascular coil occlusion of 152 middle cerebral artery aneurysms: initial and midterm angiographic and clinical results. J Neurosurg (2010) 112:703-8. doi:10.3171/2009.6.JNS09483

29. Zaidat OO, Castonguay AC, Teleb MS, Asif K, Gheith A, Southwood C, et al. Middle cerebral artery aneurysm endovascular and surgical therapies: comprehensive literature review and local experience. Neurosurg Clin N Am (2014) 25:455-69. doi:10.1016/j.nec.2014.04.005

30. Aguilar-Pérez M, Kurre W, Fischer S, Bäzner H, Henkes H. Coil occlusion of wide-neck bifurcation aneurysms assisted by a novel intra- to extraaneurysmatic neck-bridging device (pCONus): initial experience. AJNR Am J Neuroradiol (2014) 35:965-71. doi:10.3174/ajnr.A3807

31. Gory B, Aguilar-Pérez M, Pomero E, Turjman F, Weber W, Fischer S, et al. pCONus device for the endovascular treatment of wide-neck middle cerebral artery aneurysms. AJNR Am J Neuroradiol (2015) 36:1735-40. doi:10.3174/ ajnr.A4392

32. Caroff J, Mihalea C, Dargento F, Neki H, Ikka L, Benachour N, et al. Woven endobridge (WEB) device for endovascular treatment of ruptured intracranial wide-neck aneurysms: a single-center experience. Neuroradiology (2014) 56:755-61. doi:10.1007/s00234-014-1390-7

33. Klisch J, Sychra V, Strasilla C, Liebig T, Fiorella D. The woven endobridge cerebral aneurysm embolization device (WEB II): initial clinical experience. Neuroradiology (2011) 53:599-607. doi:10.1007/s00234-0110891-x

34. Ding YH, Lewis DA, Kadirvel R, Dai D, Kallmes DF. The woven endobridge: a new aneurysm occlusion device. AJNR Am J Neuroradiol (2011) 32:607-11. doi:10.3174/ajnr.A2399

35. Lubicz B, Klisch J, Gauvrit JY, Szikora I, Leonardi M, Liebig T, et al. WEB-DL endovascular treatment of wide-neck bifurcation aneurysms: short- and midterm results in a European Study. AJNR Am J Neuroradiol (2014) 35:432-8. doi:10.3174/ajnr.A3869 
36. Eboli P, Ryan RW, Alexander JE, Alexander MJ. Evolving role of endovascular treatment for MCA bifurcation aneurysms: case series of 184 aneurysms and review of the literature. Neurol Res (2014) 36:332-8. doi:10.1179/1743 132814Y.0000000324

37. Cognard C, Januel AC. Remnants and recurrences after the use of the WEB intrasaccular device in large-neck bifurcation aneurysms. Neurosurgery (2015) 76:522-30. doi:10.1227/NEU.0000000000000669

38. Alderazi YJ, Shastri D, Kass-Hout T, Prestigiacomo CJ, Gandhi CD. Flow diverters for intracranial aneurysms. Stroke Res Treat (2014) 2014:e415653. doi:10.1155/2014/415653

39. Neki H, Caroff J, Jittapiromsak P, Benachour N, Mihalea C, Ikka L, et al. Patency of the anterior choroidal artery covered with a flow-diverter stent. J Neurosurg (2015) 123:1540-5. doi:10.3171/2014.11.JNS141603

40. Puffer RC, Kallmes DF, Cloft HJ, Lanzino G. Patency of the ophthalmic artery after flow diversion treatment of paraclinoid aneurysms. J Neurosurg (2012) 116:892-6. doi:10.3171/2011.11.JNS111612

41. Rangel-Castilla L, Munich SA, Jaleel N, Cress MC, Krishna C, Sonig A, et al. Patency of anterior circulation branch vessels after pipeline embolization: longer-term results from 82 aneurysm cases. J Neurosurg (2016) 10:1-6. doi:10.3171/2016.4.JNS16147

42. Yavuz K, Geyik S, Saatci I, Cekirge HS. Endovascular treatment of middle cerebral artery aneurysms with flow modification with the use of the pipeline embolization device. AJNR Am J Neuroradiol (2014) 35:529-35. doi:10.3174/ ajnr.A3692

43. Caroff J, Neki H, Mihalea C, D’Argento F, Abdel Khalek H, Ikka L, et al. Flow-diverter stents for the treatment of saccular middle cerebral artery bifurcation aneurysms. AJNR Am J Neuroradiol (2016) 37(2):279-84. doi:10.3174/ajnr.A4540

44. Briganti F, Delehaye L, Leone G, Sicignano C, Buono G, Marseglia M, et al. Flow diverter device for the treatment of small middle cerebral artery aneurysms. J Neurointerv Surg (2016) 8:287-94. doi:10.1136/ neurintsurg-2014-011460

45. Topcuoglu OM, Akgul E, Daglioglu E, Topcuoglu ED, Peker A, Akmangit I, et al. Flow diversion in middle cerebral artery aneurysms: is it really an all-purpose treatment? World Neurosurg (2016) 87:317-27. doi:10.1016/j. wneu.2015.11.073

46. Saleme S, Iosif C, Ponomarjova S, Mendes G, Camilleri Y, Caire F, et al. Flow-diverting stents for intracranial bifurcation aneurysm treatment. Neurosurgery (2014) 75:623-31; quiz 631. doi:10.1227/NEU.0000000000000522
47. Fahed R, Gentric JC, Salazkin I, Gevry G, Raymond J, Darsaut TE. Flow diversion of bifurcation aneurysms is more effective when the jailed branch is occluded: an experimental study in a novel canine model. J Neurointerv Surg (2016). doi:10.1136/neurintsurg-2015-012240

48. Aurboonyawat T, Blanc R, Schmidt P, Piotin M, Spelle L, Nakib A, et al. An in vitro study of silk stent morphology. Neuroradiology (2011) 53:659-67. doi:10.1007/s00234-010-0784-4

49. Darsaut TE, Bing F, Salazkin I, Gevry G, Raymond J. Flow diverters failing to occlude experimental bifurcation or curved sidewall aneurysms: an in vivo study in canines. J Neurosurg (2012) 117:37-44. doi:10.3171/2012.4.JNS111916

50. van Dijk JM, Groen RJ, Ter Laan M, Jeltema JR, Mooij JJ, Metzemaekers JD. Surgical clipping as the preferred treatment for aneurysms of the middle cerebral artery. Acta Neurochir (Wien) (2011) 153:2111-7. doi:10.1007/ s00701-011-1139-6

51. Choi SW, Ahn JS, Park JC, Kwon DH, Kwun BD, Kim CJ. Surgical treatment of unruptured intracranial middle cerebral artery aneurysms: angiographic and clinical outcomes in 143 aneurysms. J Cerebrovasc Endovasc Neurosurg (2012) 14:289. doi:10.7461/jcen.2012.14.4.289

52. Rodríguez-Hernández A, Sughrue ME, Akhavan S, Habdank-Kolaczkowski J, Lawton MT. Current management of middle cerebral artery aneurysms: surgical results with a 'clip first' policy. Neurosurgery (2013) 72:415-27. doi:10.1227/NEU.0b013e3182804aa2

53. Yang W, Huang J. Treatment of middle cerebral artery (MCA) aneurysms: a review of the literature. Chin Neurosurg J (2015) 1:1. doi:10.1186/ s41016-015-0001-8

Conflict of Interest Statement: MAP and PB serve as proctors and consultants for phenox $\mathrm{GmbH}$ with moderate financial compensation. $\mathrm{HH}$ is a co-founder and shareholder of phenox GmbH. The other authors declare no conflict of interest.

Copyright (c) 2017 Bhogal, AlMatter, Bäzner, Ganslandt, Henkes and Aguilar Pérez. This is an open-access article distributed under the terms of the Creative Commons Attribution License (CC BY). The use, distribution or reproduction in other forums is permitted, provided the original author(s) or licensor are credited and that the original publication in this journal is cited, in accordance with accepted academic practice. No use, distribution or reproduction is permitted which does not comply with these terms. 